\title{
Dietary interventions for weight loss and cardiovascular risk reduction in people of African ancestry (blacks): a systematic review
}

\author{
G Osei-Assibey ${ }^{1, *}$ and C Boachie ${ }^{2}$ \\ 'Abacus International, 4 Market Square, Bicester, Oxfordshire, OX26 6AA, UK: ${ }^{2}$ Health Services Research Unit, \\ University of Aberdeen, Aberdeen, UK
}

Submitted 17 August 2010: Accepted 14 April 2011: First published online 1 June 2011

\begin{abstract}
Objective: To systematically review weight and cardiovascular risk reduction in blacks by diet and lifestyle changes.

Design: Randomised and non-randomised controlled trials of diet with/without lifestyle changes with duration of intervention $\geq 3$ months, and published between January 1990 and December 2009, were searched in electronic databases including MEDLINE, EMBASE, CINAHL and CCTR (Cochrane Controlled Trials Register). Studies were included if they reported weight/BMI changes with changes in at least one of the following: systolic and diastolic blood pressure, fasting plasma lipids and glucose, and glycated haemoglobin.

Setting: Clinical, community and church-based interventions.

Subjects: Study participants were of African ancestry (blacks).

Results: Eighteen studies met the inclusion criteria. Average mean difference in weight loss was $-2.66 \mathrm{~kg}$, with improvements in all outcomes except total cholesterol. No significant difference was observed in outcome measures between all studies and studies that recruited only healthy participants or patients with type 2 diabetes.

Conclusions: Diet and lifestyle changes result in weight loss with improvements in cardiovascular risk factors in blacks. However, more culturally tailored programmes have been suggested to motivate and encourage blacks to participate in intervention trials.
\end{abstract}

Obesity poses a major public health problem worldwide, driving an epidemic of associated complications such as type 2 diabetes mellitus and $\mathrm{CVD}^{(1)}$. People of sub-Saharan African ancestry (blacks) in Western countries exhibit higher prevalences of obesity and obesity-related cardiovascular disease risk factors than people of European ancestry (whites).

Surveys in the USA have indicated that the prevalence of obesity is $32 \cdot 2 \%$ in the general population, $30 \cdot 6 \%$ in whites and $45.0 \%$ in blacks. Among men, the prevalence is similar in whites $(31 \cdot 1 \%)$ and blacks $(34 \cdot 0 \%)$. However, black women are more likely to be obese $(53.9 \%)$ than white women $(30 \cdot 2 \%)^{(2)}$. In addition to higher obesity rates, blacks have higher prevalences of CVD risk factors, including higher prevalences of diabetes, hypertension and stroke ${ }^{(3-6)}$, and higher mortality rates from $\mathrm{CVD}^{(7)}$ compared with whites.

The higher prevalence of obesity and CVD risk factors in blacks can be ameliorated by effective weight management. However, this is both a clinical and a public health challenge, as evidence from trials indicates that blacks underachieve in weight management programmes compared with whites ${ }^{(8-13)}$. Various reasons have been proposed for this including social and cultural barriers such as differential body-image ideals, cultural food attitudes, fewer models for physical activity, and normative views of overweight and obesity ${ }^{(14,15)}$.

No review has been identified focusing on the effect of weight change by dietary and other lifestyle changes on risk factors in blacks. The present review is therefore opportune, given the higher cardiovascular risk in blacks, exacerbated by limited access to the knowledge or resources required to incorporate dietary and lifestyle changes ${ }^{(16)}$.

\section{Methods}

\section{Data sources and study selection}

The following sources were searched: MEDLINE, EMBASE, CINAHL and CCTR (Cochrane Controlled Trials Register). Reference lists of original studies and other systematic reviews were also examined. Keywords used included 'blacks' or 'black Africans' or 'African Americans' or 'Afro-Caribbeans' or 'black British' or 'black Americans' and 'obesity' or 'overweight' or 'diabetes' or 'heart disease' or 'cardiovascular disease' or 'hypertension' in combination 
with 'intervention' or 'trial' using various suffixes. Electronic searches and reviewing of results were performed by one reviewer (G.O.A.).

Another reviewer (C.B.) assessed the relevance of identified studies for inclusion, and disagreements were resolved by consensus. Studies were included on the basis of: (i) dietary intervention with/without lifestyle change (behaviour change and physical activity) $v$. control; (ii) randomised or non-randomised controlled trials; (iii) black participants (for studies made up of mixed ethnicity, authors were contacted for subgroup results on blacks); (iv) duration of intervention $\geq 3$ months; (v) studies published between January 1990 and December 2009; and (vi) reported weight/BMI change and change in at least one of the following: waist circumference, systolic and diastolic blood pressures, fasting plasma lipids and glucose, and glycated haemoglobin (HbA1c).

\section{Data synthesis}

A QUOROM (quality of reporting of meta-analysis) statement was used to describe how studies identified through the searches were processed ${ }^{(17)}$. Each study was summarized with regard to characteristics of participants and interventions, duration and dropout rate. Because of the various dietary interventions employed, results of included studies were not pooled but rather expressed as the average mean difference between intervention and control using StatsDirect Statistical Software version $2 \cdot 7 \cdot 7$ (StatsDirect Ltd, Altrincham, UK).

\section{Results}

\section{Findings and description of studies}

Search results are summarized in the QUOROM flow diagram (Fig. 1). Eighteen studies met the inclusion criteria out of thirty-five potential studies ${ }^{(18-35)}$. Seven of the studies recruited healthy obese participants, ten enrolled only participants with diabetes ${ }^{(18,19,21,23,26,30,31,33-35)}$ and one study recruited participants with hypertension ${ }^{(32)}$. Intervention duration ranged from 3.5 to 12 months (median of 6 months).

All studies took place in the USA, and about $50 \%$ of the included trials recruited less than 100 participants in the either intervention or control arm. Furthermore all studies

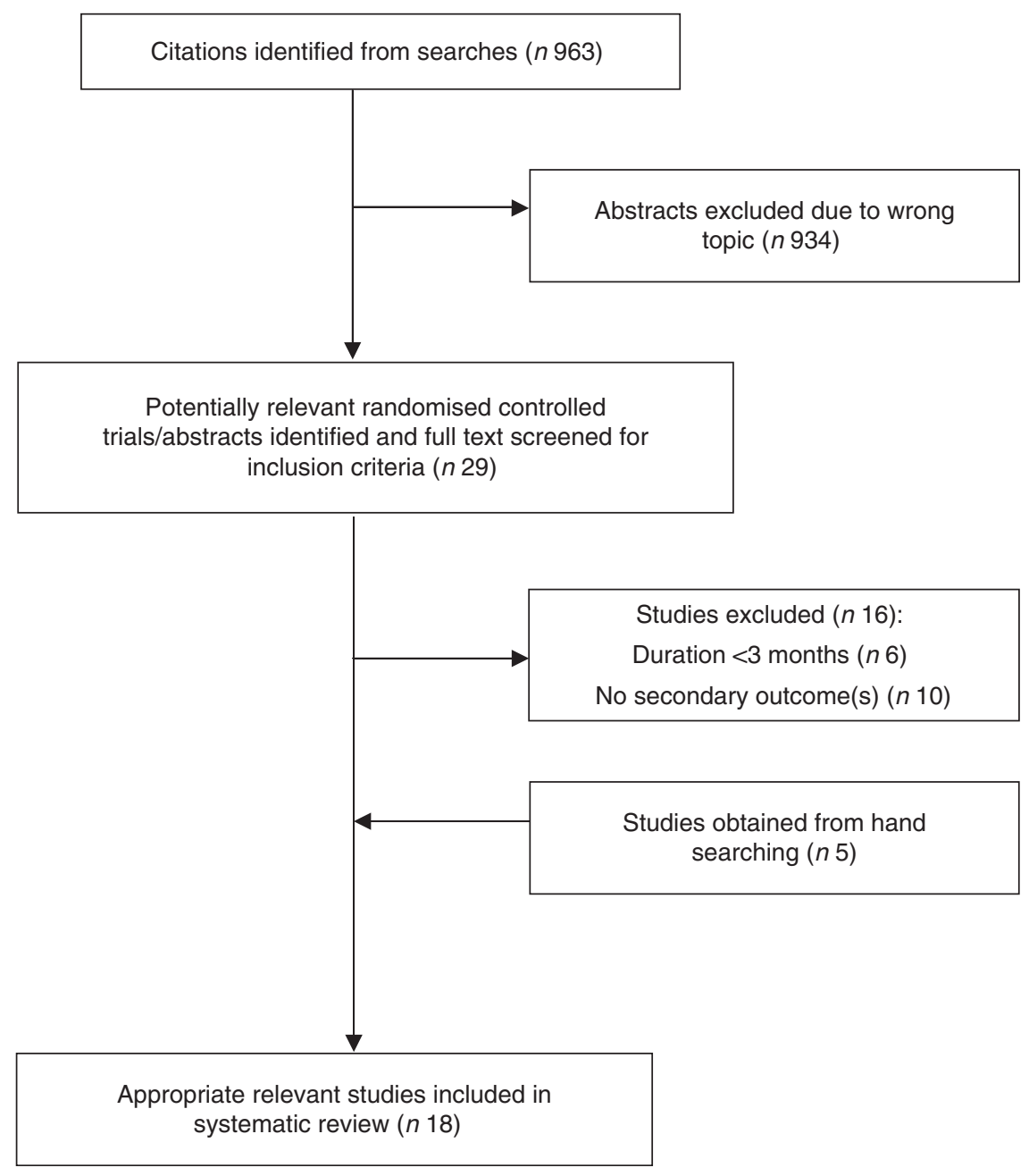

Fig. 1 QUOROM (quality of reporting of meta-analysis) flowchart 
employed dietary interventions/advice with lifestyle modifications (behaviour change and physical activity).

The majority (fifteen of eighteen) of the trials that were described as randomised specified eligibility criteria, but none explicitly stated the method of randomisation and details of allocation concealment in the trials. Incomplete outcome data were addressed in ten of eighteen trials. Six studies recruited only women participants ${ }^{(22,24,26-29)}$ and the rest were of mixed gender. Most of the studies were clinic- or community-based, and only three were church-based $^{(22-24)}$. Attrition rate ranged from $6 \%$ to $32 \%$. Table 1 summarises the characteristics of the participants and interventions.

\section{Outcomes}

All studies showed a positive treatment effect on weight change between intervention and control except two studies $^{(20,23)}$. Net average weight loss ranged from $5 \cdot 40 \mathrm{~kg}$ in 3.5 months ${ }^{(35)}$ to $2 \cdot 49 \mathrm{~kg}$ in 6 months ${ }^{(18,19,22,26-29,31-33)}$ and $2 \cdot 91 \mathrm{~kg}$ in 12 months ${ }^{(20,21,23-25,30,34)}$. Average mean difference in weight loss was $-2.66 \mathrm{~kg}$ for all studies, $-2.63 \mathrm{~kg}$ for studies that recruited healthy participants and $-2 \cdot 76 \mathrm{~kg}$ for studies that enrolled only patients with type 2 diabetes. Even though weight loss in type 2 diabetes patients was higher, it was not significantly different from weight loss in all studies or in healthy participants (Table 2).

Weight loss was associated with net improvements in waist circumference $(-2.95 \mathrm{~cm})$, fasting blood glucose $(-0.82 \mathrm{mmol} / \mathrm{l}), \mathrm{HbA1c}(-0.51 \%)$, systolic $(-1.4 \mathrm{mmHg})$ and diastolic blood pressures $(-0.6 \mathrm{mmHg})$, LDL cholesterol $(-0.06 \mathrm{mmol} / \mathrm{l})$, HDL cholesterol $(+0.31 \mathrm{mmol} / \mathrm{l})$ and TAG $(-0 \cdot 29 \mathrm{mmol} / \mathrm{l})$, but not in total cholesterol. No significant difference was detected between all studies and the studies of healthy participants or type 2 diabetes patients for any outcome (Table 2).

\section{Discussion}

The higher prevalence of cardiovascular risk factors in blacks has been attributed to multiple influences of genetics, socio-economic factors and lifestyle that promote obesity and make weight loss difficult ${ }^{(36-40)}$. Reducing CVD risk factors in blacks by weight control has therefore not been effective, probably due to a lack of cultural competency in weight management programmes coupled with a failure to address issues of relevance to the population ${ }^{(41,42)}$. Additionally there is paucity of high-quality data on diet and lifestyle interventions for weight and cardiovascular risk reduction in people of African ancestry, and this gap presents a major hurdle in developing effective policies and programmes ${ }^{(43)}$.

Reviews on weight management interventions in minorities have been published recently ${ }^{(44,45)}$, but the magnitude of the average net treatment effect on cardiovascular risk reduction has not been studied in people of African ancestry. Eighteen out of thirty-five potential studies fulfilled the inclusion criteria of the present review. Most of the potential studies that were excluded targeted weight management without assessment of its impact on cardiovascular risk reduction.

The net average weight loss of $2.7 \mathrm{~kg}$ found in the present review is lower than that reported previously in mostly white Caucasian populations $(-5.0 \mathrm{~kg}$, range $-0 \cdot 40$ to $-7 \cdot 80 \mathrm{~kg})$ using standard $2510 \mathrm{~kJ} / \mathrm{d}(600 \mathrm{kcal} / \mathrm{d})$ deficit and low-fat diets for $\geq 12$ months ${ }^{(46)}$. However, the results are comparable to analyses which showed, for each kilogram of weight loss, that systolic and diastolic blood pressures fall by $1.0 \mathrm{mmHg}$ each $^{(47)}$ and blood parameters improve: total cholesterol by $-0.13 \mathrm{mmol} / 1$, TAG by $-0.09 \mathrm{mmol} / 1$, LDL cholesterol by $-0.05 \mathrm{mmol} / 1$, HDL cholesterol by $+0.004 \mathrm{mmol} / \mathrm{l}^{(48)}$ and fasting plasma glucose by $-0 \cdot 2 \mathrm{mmol} / \mathrm{l}^{(49)}$.

Although the clinical significance of the results of the present review cannot be fully determined, one cannot dismiss its public health relevance in blacks. This is because studies have intimated that reductions in the incidence of type 2 diabetes and CVD can be achieved by sustained lifestyle changes ${ }^{(18,50-52)}$.

Results of the Diabetes Prevention Programme (DPP) in which $19 \cdot 9 \%$ of participants were blacks ${ }^{(50,51)}$ and the Look AHEAD study ${ }^{(34)}$ in which $15 \cdot 5 \%$ of participants were blacks all provide a standard for weight management for the control of risk factors in blacks. Findings of the DPP and Look AHEAD should therefore be of interest to clinicians and public health researchers who are interested in implementing interventions in people of African ancestry. It must however be recognised that participants in the DPP were rigorously selected to be highly motivated and the intervention was resource-intensive to deliver ${ }^{(28,51)}$.

Some of the studies included in the present review suffered from limitations, including small number of participants, lack of power to detect significant changes and high attrition rates. Some of the studies attempted to address the higher attrition rates by using the last observation carried forward (LOCF). However, such analysis underestimates or overestimates the results, depending on different dropout rates in treatment and control groups ${ }^{(53)}$.

The present review has highlighted a serious deficiency of published research in an increasingly important area in people of African ancestry. Although interesting, the studies that have been published have used various approaches which have suggested improvement in weight and cardiovascular risk factor reduction in the medium term ( 6 months). However, changing attitudes may not by themselves lead to sustained behaviour change if the environment is not supportive of these changes ${ }^{(54)}$. More studies are therefore needed: first to examine the 'obesogenic' environment, health beliefs and the social context within which blacks live and work, and second to examine the motivators for behaviour change within this population. 
Table 1 Key characteristics of studies included in the present review on dietary interventions for weight loss and cardiovascular risk reduction in blacks

\begin{tabular}{|c|c|c|c|c|c|}
\hline Study & $\begin{array}{l}\text { Mean age } \\
\text { (years) }\end{array}$ & $\begin{array}{l}\text { Mean BMI } \\
\left(\mathrm{kg} / \mathrm{m}^{2}\right)\end{array}$ & Intervention $v$. control & $\begin{array}{l}\text { Length of } \\
\text { intervention } \\
\text { (months) }\end{array}$ & $\begin{array}{l}\text { Dropout } \\
\text { rate }(\%)\end{array}$ \\
\hline Agurs-Collins et al. (1997) ${ }^{(18)}$ & $61 \cdot 8$ & $33 \cdot 9$ & $\begin{array}{l}\text { Weekly sessions on dietary advice and exercise }(n 30) v \text {. class session and informational } \\
\text { mailings }(n 25)\end{array}$ & 6 & 14 \\
\hline Anderson-Loftin et al. (2005) ${ }^{(19)}$ & 57.3 & 33.1 & Low-fat diet advice plus peer group discussions $(n$ 38) $v$. usual diabetes care class $(n 27)$ & 6 & 23 \\
\hline Becker et al. $(2005)^{(20)}$ & 47.8 & 31.5 & $\begin{array}{l}\text { Lifestyle advice to reduce heart disease }(n 196) v \text {. enhanced primary care to reduce heart } \\
\text { disease }(n 168)\end{array}$ & 12 & 27 \\
\hline Racette et al. $(2001)^{(21)}$ & 47.5 & 40.0 & Diet and activity advice sessions $(n 19) v$. one diet and activity session $(n 17)$ & 12 & 24 \\
\hline Resnicow et al. (2005) & 13.8 & 32.7 & $\begin{array}{l}\text { High-intensity behavioural group intervention ( } n \text { 53) v. moderate-intensity behavioural group } \\
\text { intervention }(n 70)\end{array}$ & 6 & 21 \\
\hline Samuel-Hodge et al. (2009) ${ }^{(23)}$ & $59 \cdot 0$ & $35 \cdot 0$ & Individual counselling plus group sessions $(n 96) v$. standard educational pamphlets by mail $(n 72)$ & 12 & 16 \\
\hline Yanek et al. (2001) (24) & $53 \cdot 1$ & $32 \cdot 2$ & Healthy lifestyle sessions plus spiritual components $(n 455) v$. self-help information $(n 74)$ & 12 & 25 \\
\hline Zemel et al. (2005) (25) & $41 \cdot 9$ & $34 \cdot 5$ & High dairy/calcium plus energy restriction $(n 17) v$. low dairy/calcium plus energy restriction $(n 12)$ & 12 & 19 \\
\hline West et al. (2007) & 53 & $36 \cdot 5$ & $\begin{array}{l}\text { Individual motivational interviewing }(n 42) v \text {. attention as adjunct to behavioural weight-control } \\
\text { programme }(n 41)\end{array}$ & 6 & 16 \\
\hline Hall et al. (2003) $)^{(27)}$ & $59 \cdot 9$ & $28 \cdot 9$ & $\begin{array}{l}\text { Reduction in total fat intake to } \leq 20 \% \text { of energy }(n 335) v \text {. pamphlet on general dietary guidelines } \\
(n 203)\end{array}$ & 6 & 15 \\
\hline Samaha et al. (2003) ${ }^{(28)}$ & $53 \cdot 5$ & $42 \cdot 9$ & Low-carbohydrate diet ( $\leq 30 \mathrm{~g} / \mathrm{d} ; n 43) v$. low-fat diet ( $\leq 30 \%$ of total energy derived from fat; $n 36$ ) & 6 & 25 \\
\hline Kennedy et al. (2009) ${ }^{(29)}$ & $45 \cdot 9$ & $33 \cdot 7$ & Classroom peer nutrition and physical activity lessons $(n 18) v$. monthly take home lessons $(n 19)$ & 6 & 0 \\
\hline Mayer-Davis et al. (2004) ${ }^{(30)}$ & $61 \cdot 1$ & $36 \cdot 4$ & Intensive diabetes prevention programme $(n 49) v$. usual care (one individual session; $n$ 56) & 12 & 21 \\
\hline Ziemer et al. $(2003)^{(31)}$ & $52 \cdot 0$ & $33 \cdot 5$ & Healthy food meal plan ( $n$ 289) v. exchange-based meal plan $(n$ 359) & 6 & 32 \\
\hline Elmer et al. (2006) ${ }^{(32)}$ & $49 \cdot 9$ & $33 \cdot 1$ & Comprehensive lifestyle modification ( $n 79) v$. advice only ( $n$ 100) & 6 & 12 \\
\hline Barnard et al. (2006) ${ }^{(33)}$ & $55 \cdot 6$ & 34.9 & Low-fat vegan diet $(n$ 22) $v$. American Diabetes Association guideline ( $n$ 22) & $5 \cdot 5$ & 8 \\
\hline Look AHEAD Research Group ${ }^{(34)}$ & $58 \cdot 7$ & $36 \cdot 4$ & $\begin{array}{l}\text { Lifestyle intervention of group and individual meetings ( } n \text { 399) v. diabetes support and } \\
\text { education ( } n \text { 404) }\end{array}$ & 12 & 15 \\
\hline McNabb et al. $(1997)^{(35)}$ & $56 \cdot 6$ & $33 \cdot 5$ & PATHWAYS weight-loss programme $(n 15) v$. wait list control group $(n 18)$ & 3.5 & 6 \\
\hline
\end{tabular}


Table 2 Outcome measures (expressed as average mean difference between intervention and control) of dietary interventions for weight loss and cardiovascular risk reduction in blacks ${ }^{(18-35)}$

\begin{tabular}{lccc}
\hline Outcome & All studies & Healthy participants & Patients with type 2 diabetes \\
\hline Weight (kg) & -2.66 & -2.63 & $-2 \cdot 76$ \\
Waist circumference (cm) & -2.95 & -2.26 & -3.63 \\
Systolic blood pressure (mmHg) & -1.39 & -1.54 & $-0 \cdot 70$ \\
Diastolic blood pressure (mmHg) & -0.61 & -0.77 & -0.69 \\
Fasting blood glucose (mmol/l) & -0.82 & -0.2 & $-1 \cdot 73$ \\
Glycated haemoglobin, HbA1c (\%) & -0.51 & - & -0.57 \\
HDL cholesterol (mmol/l) & 0.31 & 0.19 & 0.38 \\
LDL cholesterol (mmol/l) & -0.06 & -0.11 & -0.04 \\
Total cholesterol (mmol/l) & 0.87 & 0.27 & $1 \cdot 10$ \\
TAG (mmol/l) & -0.29 & -0.86 & -0.04 \\
\hline
\end{tabular}

Cultural adaptations in interventions involving blacks have also been suggested, such as involving black providers, using a community setting, using the group's preferred language, and incorporating cultural food and activity preferences, traditions and concepts into programme content.

\section{Acknowledgements}

This research received no funding or grant from any funding agency in the public, commercial or not-for-profit sector. There is no conflict of interest. G.O.A. did the initial searching in electronic databases and hand searching, and also wrote the first draft of the paper. C.B. did the selection of studies based on the inclusion criteria, and also contributed to the final draft and statistical advice.

\section{References}

1. James WP (2008) The epidemiology of obesity: the size of the problem. J Intern Med 263, 336-352.

2. Ogden CL, Carrol MD, Curtin LR et al. (2006) Prevalence of overweight and obesity in the United States, 1999-2004. JAMA 295, 1549-1555.

3. Wild S \& McKeigue P (1997) Mortality by country of birth in England and Wales. BMJ 314, 689-762.

4. Cappuccio FP, Cook DG, Atkinson RW et al. (1997) Prevalence, detection, and management of cardiovascular risk factors in different ethnic groups in south London. Heart 78, 555-563.

5. Zoratti RA (1998) Review on ethnic differences in plasma triglycerides and high-density lipoprotein cholesterol: is the lipid pattern the key factor for the low coronary heart disease rate in people of African origin? Eur J Epidemiol 14, 9-21.

6. Chaturvedi N, McKeigue PM \& Marmot MG (1993) Resting and ambulatory blood pressure differences in AfroCaribbeans and Europeans. Hypertension 22, 90-96.

7. US Census Bureau (2000) Profiles of General Demographic Characteristics: 2000 Census of Population and Housing, United States. Washington, DC: US Census Bureau.

8. Parikh M, Lo H, Chang C et al. (2006) Comparison of outcomes after laparoscopic adjustable gastric banding in AfricanAmericans and whites. Surg Obes Relat Dis 2, 607-610.

9. Kumanyika SK, Obarzanek E, Stevens VJ et al. (1991) Weight-loss experience of black and white participants in NHLBI-sponsored clinical trials. Am J Clin Nutr 53, 6 Suppl., 1631S-1638S.
10. Buffington CK \& Marema RT (2006) Ethnic differences in obesity and surgical weight loss between African-American and Caucasian females. Obes Surg 16, 159-165.

11. Hong K, Li Z, Wang H-J et al. (2005) Analysis of weight loss outcomes using VLCD in black and white overweight and obese women with and without metabolic syndrome. Int J Obes (Lond) 29, 436-442.

12. Wing RR \& Anglin K (1996) Effectiveness of a behavioural weight control program for blacks and whites with NIDDM. Diabetes Care 19, 409-413.

13. McMahon FG, Fujioka K, Singh BN et al. (2000) Efficacy and safety of sibutramine in obese white and African American patients with hypertension. Arch Intern Med 160, 2185-2191.

14. Cooper R, Kennelly JF, Durazo-Arvizu R et al. (2001) Relationship between premature mortality and socioeconomic factors in black and white populations of US metropolitan areas. Public Health Rep 116, 464-473.

15. Kumanyika SK (2002) The minority factor in the obesity epidemic. Ethn Dis 12, 316-319.

16. Kumanyika SK (2008) Environmental influences on childhood obesity: ethnic and cultural influences in context. Physiol Behav 94, 61-70.

17. Moher D, Cook DJ, Eastwoods S et al. (1999) Improving the quality of reports of meta-analysis of randomised controlled trials: the QUOROM Statement. Lancet 354, 896-900.

18. Agurs-Collins T, Kumanyika SK, Have TR et al. (1997) A randomized controlled trial of weight reduction and exercise for diabetes management in older African American subjects. Diabetes Care 20, 1503-1510.

19. Anderson-Loftin W, Barnett S, Bunn P et al. (2005) Soul food light: culturally competent diabetes education. Diabetes Educ 31, 555-563.

20. Becker DM, Yanek LR, Johnson WR Jr et al. (2005) Impact of a community-based multiple risk factor intervention on cardiovascular risk in black families with a history of premature coronary disease. Circulation 111, 1298-1304.

21. Racette SB, Weiss EP, Obert KA et al. (2001) Modest lifestyle intervention and glucose tolerance in obese African Americans. Obes Res 9, 348-355.

22. Resnicow K, Taylor R, Baskin M et al. (2005) Results of Go Girls: a weight control program for overweight AfricanAmerican adolescent females. Obes Res 13, 1739-1748.

23. Samuel-Hodge CD, Keyserling TC, Park S et al. (2009) A randomized trial of a church-based diabetes self-management program for African Americans with type 2 diabetes. Diabetes Educ 35, 439-454.

24. Yanek LR, Becker DM, Moy TF et al. (2001) Project Joy: faith based cardiovascular health promotion for African American women. Public Health Rep 116, 68-81. 
25. Zemel MB, Richards J, Milstead A et al. (2005) Effects of calcium and dairy on body composition and weight loss in African American adults. Obes Res 13, 1218-1225.

26. West DS, Dilillo V, Bursac Z et al. (2007) Motivational interviewing improves weight loss in women with type 2 diabetes. Diabetes Care 30, 1081-1087.

27. Hall WD, Feng Z, George VA et al. (2003) Low fat diet: effect on anthropometrics, blood pressure, glucose, and insulin in older women. Ethn Dis 13, 337-343.

28. Samaha FF, Iqbal N, Seshadri P et al. (2003) A lowcarbohydrate as compared with a low-fat diet in severe obesity. N Engl J Med 348, 2074-2081.

29. Kennedy BM, Champagne CM, Ryan DH et al. (2009) The 'Rolling Store': an economical and environmental approach to the prevention of weight gain in African American women. Ethn Dis 19, 7-12.

30. Mayer-Davis E, D'Antonio AM, Smith SM et al. (2004) Pounds off with empowerment (POWER): a clinical trial of weight management strategies for black and white adults with diabetes who live in medically underserved rural communities. Am J Public Health 94, 1736-1742.

31. Ziemer DC, Berkowitz KJ, Panayioto RM et al. (2003) A simple meal plan emphasizing healthy food choices is as effective as an exchange-based meal plan for urban African Americans with type 2 diabetes. Diabetes Care 26, $1719-1724$.

32. Elmer PJ, Obarzanek E, Vollme WM et al. (2006) Effects of comprehensive lifestyle modification on diet, weight, physical fitness, and blood pressure control: 18-month results of a randomized trial. Ann Intern Med 144, 485-495.

33. Barnard ND, Cohen J, Jenkins DJA et al. (2006) A low-fat vegan diet improves glycemic control and cardiovascular risk factors in a randomized clinical trial in individuals with type 2 diabetes. Diabetes Care 29, 1777-1783.

34. Look AHEAD Research Group (2007) Reduction in weight and cardiovascular disease risk factors in individuals with type 2 diabetes: one-year results of the Look AHEAD trial. Diabetes Care 30, 1374-1383.

35. McNabb W, Quinn M, Kerver J et al. (1997) The PATHWAYS church-based weight loss program for urban AfricanAmerican women at risk for diabetes. Diabetes Care 20, 1518-1523.

36. Chiu KC, Province MA \& Permutt MA (1992) Glucokinase gene is genetic marker for NIIDM in American blacks. Diabetes 41, 834-849.

37. Cowie CC, Harris MI, Silverman RE et al. (1993) Effects of multiple risk factors on differences between blacks and whites in the prevalence of non-insulin-dependent diabetes mellitus in the United States. Am J Epidemiol 137, 719-731.

38. Berg J \& Berg BL (1989) Compliance, diet, and cultural factors among black Americans with end-stage renal disease. J Natl Black Nurses Assoc 3, 16-28.

39. Airhihenbuwa CO, Kumanyika SK, Argurs TD et al. (1996) Cultural aspects of African-American eating patterns. Ethn Health 1, 245-260.
40. Tull ES \& Roseman M (1995) Diabetes in African Americans. In Diabetes in America, 2nd ed. NIH Publication no. 95-1468, pp. 613-629 [National Diabetes Data Group, editor]. Washington, DC: National Institutes of Health.

41. Kumanyika SK \& Ewart CK (1990) Theoretical and baseline considerations for diet and weight control of diabetes among blacks and whites. Diabetes Care 13, Suppl. 4, 1154-1162.

42. Maillet NA, Melkus GD \& Spollett G (1996) Using focus groups to characterize the health beliefs and practices of black women with non-insulin-dependent diabetes. Diabetes Educ 22, 39-46.

43. Yancey AK, Kumanyika SK, Ponce NA et al. (2004) Population-based interventions engaging communities of color in healthy eating and active living: a review. Prev Chronic Dis 1, A09.

44. Seo D-C \& Sa J (2008) A meta-analysis of psychobehavioural obesity Interventions among US multiethnic and minority adults. Prev Med 47, 573-582.

45. Osei-Assibey G, Kyrou I, Adi Y et al. (2010) Dietary and lifestyle interventions for weight management in adults from minority/non-white groups: a systematic review. Obes Rev 11, 769-776.

46. National Institute for Health and Clinical Excellence (2006) Section 5b: Management of obesity 2. In Obesity: The Prevention, Identification, Assessment and Management of Overweight and Obesity in Adults and Children. Full Guidance FINAL VERSION (December 2006), pp. 532-542. London: NICE.

47. Neter JE, Stam BE, Kok FJ et al. (2003) Influence of weight reduction on blood pressure. A meta-analysis of randomised controlled trials. Hypertension 42, 878-884.

48. Dattilo AM \& Kris-Etherton PM (1992) Effects of weight reduction on blood lipids and lipoproteins: a meta-analysis. Am J Clin Nutr 56, 320-328.

49. Anderson JW \& Konz EC (2001) Obesity and disease management: effects of weight loss on comorbid conditions. Obes Res 9, Suppl. 4, 326S-334S.

50. Diabetes Prevention Program (DPP) Research Group (2002) Reduction in the incidence of type 2 diabetes with lifestyle intervention or metformin. $N$ Engl J Med 346, 393-403.

51. West DS, Prewitt T, Bursac Z et al. (2008) Weight loss of black, white, and hispanic men and women in the Diabetes Prevention Program. Obesity (Silver Spring) 16, 1413-1420.

52. American Dietetic Association (1997) Position of the American Dietetic Association: weight management. $J$ Am Diet Assoc 97, 71-74.

53. Padwal R, Li SK \& Lau DCW (2003) Long-term pharmacotherapy for overweight and obesity: a systematic review and meta-analysis of randomized controlled trials. Int $J$ Obes Relat Metab Disord 27, 1437-1446.

54. Kumanyika SK (2008) Ethnic minorities and weight control research priorities: where are we now and where do we need to be? Prev Med 47, 583-586. 